\title{
IMBRICAÇÕES ENTRE VIOLÊNCIA, INDISCIPLINA E GÊNERO EM LIVROS DE OCORRÊNCIAS ESCOLARES
}

\author{
OVERLAPS AMONG VIOLENCE, INDISCIPLINE AND GENDER \\ IN SCHOOL OCCURRENCE BOOKS \\ IMBRICACIONES ENTRE VIOLENCIA, INDISCIPLINA Y \\ GÉNERO EM LIBROS DE OCURRENCIAS ESCOLARES
}

\author{
Renata Maria Moschen Nascente ${ }^{i}$ \\ Maria Cecília Kerches de Menezes ${ }^{i i}$ \\ Paola Karuliny Guarnieri ${ }^{\text {iii }}$
}

\begin{abstract}
RESUMO: Com base em um recorte de pesquisa que foi desenvolvida pelo Grupo de Estudos e Pesquisas em Educação: Participação Democrática e Direitos Humanos, o objetivo deste artigo é explicitar e discutir imbricações entre violência, indisciplina e gênero em uma escola pública de educação básica por meio de registros nos seus Livros de Ocorrências Escolas - LOE, no ano de 2013, que demonstraram diferenças nos tratamentos dados a meninas e meninos no que se refere aos seus supostos atos de indisciplina, tanto quantitativamente, como qualitativamente. A abordagem metodológica foi qualitativa, exploratória e documental em educação. Foi possível evidenciar que concepções de gênero influenciaram a equipe escolar tanto no registro de atos de indisciplina como em relação às providências tomadas. Essas posturas refletem relações na escola que podem dificultar a oferta de uma educação de qualidade social na perspectiva dos direitos humanos.
\end{abstract}

PALAVRAS-ChAVE: Indisciplina. Gênero. Livros de ocorrências escolares.

ABSCTRACT: Based on part of a research that was developed by the Group of Studies and Research in Education: Democratic Participation and Human Rights, the objective of this article is to explain and discuss some overlaps among violence, indiscipline and gender in a public school of basic education through their School Occurrence Books - SOB, in the year of 2013. Those books displayed different approaches towards boys and girls regarding their alleged acts of indiscipline, both quantitatively and qualitatively. The methodological approach was qualitative, exploratory and documental in education. It was possible to evidence that gender conceptions influenced the school staff both, in registering the occurrences and in taking measures towards them. These positions reflect relationships in the school that may hinder the provision of social quality education in the human rights perspective.

KEYWORDS: Indiscipline. Gender. School occurrence books.

RESUMEN: En base a un recorte de investigación que fue desarrollado por el Grupo de Estudios e Investigaciones en Educación: Participación Democrática y Derechos Humanos, el objetivo de este artículo es explicitar y discutir imbricaciones entre violencia, indisciplina y género en una escuela pública de educación básica por medio de En el año 2013, que demuestran diferencias en los tratamientos dados a niñas y niños en lo que se refiere a sus supuestos actos de indisciplina, tanto cuantitativamente, como cualitativamente, en sus Libros de Ocurrencias Escolares - LOE, en el año 2013. El enfoque metodológico fue cualitativo, exploratorio y documental en educación. Es posible evidenciar que concepciones de género influenciaron al equipo escolar

Submetido em: 08/07/2016 - Aceito em: 14/03/2017 - Publicado em: 12/09/2017.

\begin{tabular}{l|c|c|c|c|c|c} 
(C) Rev. Educ. Perspec. & Viçosa, $M G$ & v.8 & n.2 & p.159-176 & maio/ago. 2017 & eISSN 2178-8359 \\
\hline
\end{tabular}


tanto en el registro de actos de indisciplina como en relación a las providencias tomadas. Estas posturas reflejan relaciones en la escuela que pueden dificultar la oferta de una educación de calidad social en la perspectiva de los derechos humanos.

PALABRAS ClAVE: Indisciplina. Género. Libros de ocurrencias escolares.

\section{INTRODUÇÃO}

Considerando a importância da oferta de uma educação básica de qualidade social que garanta direitos humanos fundamentais, este artigo tem como objetivo explicitar e discutir imbricações entre violência, indisciplina e gênero em uma escola pública estadual localizada no interior do estado de São Paulo, com base em dados levantados nos Livros de Ocorrências Escolas - LOE dessa escola no ano letivo de 2013, referentes a estudantes da segunda etapa do ensino fundamental e do ensino médio.

Muito comuns nas escolas públicas de educação básica, os LOE constituem-se em instrumentos utilizados pelas equipes escolares para manter a ordem e a obediência às normas estabelecidas por meio do registro das supostas infrações cometidas. Além dessa função explícita, existem outras, por exemplo, garantir que as sanções infringidas aos estudantes não se voltem contra a própria equipe, uma espécie de seguro contra reclamações de pais e até processos administrativos. Também se destaca o fato dos LOE se estabelecerem como formas de punição, isto é, espera-se que estudantes passem a não praticar atos de indisciplina, pois se sentiriam intimidados ao terem esses atos registrados nesses livros (MORO, 2003; FONSECA; SALLES; SILVA, 2014).

Constatou-se também nos LOE pesquisados que supostas infrações de meninos e meninas eram registradas de forma e com frequências diferentes. Assim, este artigo objetiva explicitar como os registros nos LOE evidenciaram diversidades nos tratamentos dados a meninas e meninos e discutir as imbricações entre indisciplina e gênero neles contidos.

A abordagem metodológica utilizada foi de natureza documental (GIL, 2002), qualitativa e exploratória em educação (BOGDAN; BIKLEN, 2010). Os aspectos exploratório e qualitativo residiram no desenvolvimento de uma investigação sem uma hipótese inicial fechada e pela própria natureza dos dados, basicamente textuais, e, portanto, qualitativos, a partir dos quais foram elaboradas hipóteses de trabalho e as categorias de análise.

A organização dos dados levantados nos LOE deu origem a algumas categorias de ocorrências, das quais se destacaram numericamente as relativas à realização de tarefas; circulação pela escola; uso de equipamentos eletrônicos, principalmente telefones celulares;

\begin{tabular}{l|c|c|c|c|c|c} 
() Rev. Educ. Perspec. & Viçosa, $M G$ & v.8 & n.2 & p.159-176 & maio/ago. 2017 & eISSN 2178-8359 \\
\hline
\end{tabular}


conversas, gritos e ruídos e manifestações de desrespeito de estudantes em relação a professores.

Assim, foi possível compreender algumas concepções de gênero vigentes na escola e como essas concepções poderiam influenciar diversos aspectos das práticas educativas, inclusive o disciplinar.

\title{
INDISCIPLINA, VIOLÊNCIA E GÊNERO NOS LOE
}

Charlot (2002, p. 434-435) faz uma distinção importante entre violência na escola, violência à escola e violência $d a$ escola:

\begin{abstract}
A violência na escola é aquela que se produz dentro do espaço escolar, sem estar ligada à natureza e às atividades da instituição escolar: quando um bando entra na escola para acertar contas das disputas que são as do bairro, a escola é apenas o lugar de uma violência que teria podido acontecer em qualquer outro local. [...] A violência à escola está ligada à natureza e às atividades da instituição escolar: quando os alunos provocam incêndios, batem nos professores ou os insultam, eles se entregam a violências que visam diretamente a instituição e aqueles que a representam. Essa violência contra a escola deve ser analisada junto com a violência $d a$ escola: uma violência institucional, simbólica, que os próprios jovens suportam através da maneira como a instituição e seus agentes os tratam (modos de composição de classes, de atribuição de notas, de orientação, palavras desdenhosas dos adultos, atos considerados pelos alunos como injustos ou racistas...).
\end{abstract}

Os registros nos LOE revelaram a existência desses três tipos de violência. No que se refere a violência $n a$ escola, ficou demonstrado que muitos conflitos que eclodiram na escola foram motivados por contendas envolvendo estudantes e membros da comunidade à noite e durante os finais de semana, períodos durante os quais a escola ficava fechada. Às segundas feiras, particularmente, diversas brigas entre estudantes eram registradas, e, no detalhamento desses registros foi possível perceber que suas motivações estavam ligadas a, por exemplo, disputas entre meninas em relação a um determinado menino, ocorridas em festas, encontros e em redes sociais. Por outro lado, a violência à escola, isto é, por ela sofrida, não foi significativamente registrada nos LOE.

Já a violência $d a$ escola evidenciou-se na análise dos registros nos LOE, levando-nos a crer que muito dessa violência ocorre em função das regras disciplinares vigentes, oriundas do sistema de ensino e/ou da própria organização escolar, que levam os profissionais da escola a punir os estudantes com advertências, suspensões e por meio dos próprios registros (MORO, 2003; FONSECA; SALLES; SILVA, 2014).

Corroborando a visão de Charlot (2002) sobre a violência na escola, à escola e da escola, Abramovay e Rua (2002) apontam que é necessário levar em conta fatores externos e internos

\begin{tabular}{l|c|c|c|c|c|c} 
(C) Rev. Educ. Perspec. & Viçosa, $M G$ & v.8 & n.2 & p.159-176 & maio/ago. 2017 & eISSN 2178-8359 \\
\hline
\end{tabular}


à instituição de ensino. Entre os fatores externos abordados pelas autoras, destacam-se as questões de gênero, as relações raciais, os meios de comunicação e o espaço social no qual a escola está inserida. Entre os fatores internos deve-se levar em consideração a compatibilidade entre idade, série e/ou nível de escolaridade dos estudantes, as regras disciplinares estabelecidas nos projetos pedagógicos das escolas, assim como o impacto do sistema de punições, o comportamento dos professores em relação aos alunos e destes em relação aos professores.

Segundo Abramovay e Rua (2002), os comportamentos interpretados como negativos pela escola são combatidos com punições específicas. Como, na maioria das vezes, elas são estipuladas de forma arbitrária, a escola pode ser um lugar privilegiado do exercício da violência simbólica, praticada pelo uso de sinais de poder que falam por si só, sem necessidade de gritos e outras manifestações mais concretas. Essa ideia nos remete a Bourdieu (1989), que explica como os sistemas simbólicos se fundamentam por relações de poder. Dessa forma, as violências simbólicas atuam como instrumentos voltados a legitimar atitudes e ações dos que estão em exercício de poder em alguma instituição, fortalecendo-os, sem que haja necessariamente o emprego da força para atingir a dominação. A violência simbólica, da escola (CHARLOT, 2002), pode contribuir para a domesticação dos que devem ser dominados, isto é, estudantes e talvez até suas famílias. São medidas que calam protestos, exercidos por meio da movimentação de estudantes por toda a escola, a recusa implícita e explícita em realizar as atividades propostas, desrespeito a professores, agressividades entre estudantes e entre eles e professores, manifestações que se destacaram nos LOE pesquisados.

A compreensão da violência na escola, segundo Debarbieux (2007), exige o entendimento de alguns de seus fatores específicos. Um deles é o que se refere ao estilo parental como um preditor, ou seja, um estilo parental repressivo e autoritário, que faz uso de castigos físicos é um dos maiores preditores de manifestações de violência por parte de crianças e jovens na escola. Outros fatores potencializadores de violência $n a$ escola seriam o insucesso escolar e fragilidades nas relações entre escolas e famílias. Há ainda os fatores ligados aos sentimentos de pertença de indivíduos em relação a grupos, propiciadores de isolamento e de bullying, o que pode aumentar consideravelmente as chances de que uma criança e/ou jovem venha a praticar atos violentos. Finalmente, o estudioso arrola alguns fatores ligados ao meio social, que estão associados à: desorganização comunitária; presença de armas e de drogas na vizinhança, exposição à violência e ao racismo, existência de adultos criminosos na comunidade, pobreza e ao baixo status social.

Vóvio et al. (2016) em seu estudo sobre livros de ocorrências em duas escolas públicas, utilizaram a categorização de Charlot (2002, p. 07) violência na, à, e da escola. 
Tais categorias constituíram-se como chaves de interpretação para o exame das ocorrências, daquilo que seus relatores, as equipes escolares, consideraram necessário ser registrado por conturbar o ambiente, atos que foram recusados e rejeitados de algum modo, discernidos por eles como contrários ao que é próprio para a convivência na escola.

Os autores Vóvio et al. (2016) reiteram em seu trabalho a polissemia de termos referentes à violência escolar, notadamente entre os conceitos de violência e indisciplina que se confundem em um largo espectro de definições. Esse problema de certa forma é resolvido por Charlot (2002), para quem a violência é um fenômeno amplo, de origem multifatorial, presente nos mais diversos segmentos e dimensões sociais, não sendo ela maior na escola pública de educação básica do que em outros espaços sociais. Ela se manifesta de várias formas na escola, por meio, por exemplo, de atos de agressividade, que seriam manifestações tangíveis, físicas e/ou verbais de conflitos entre as pessoas que convivem na escola. A violência também pode se manifestar em incivilidades que poderiam ser definidas como rupturas em relação às regras de convivência em uma determinada instância social.

Os registros nos LOE evidenciaram que a escola pesquisada reservava termos como violência para designar atos que envolviam o uso da força ou ameaças de usá-la, tais como lesões, extorsão, tráfico de drogas ou insultos graves. Palavras como agressão eram utilizadas para os comportamentos contrários ao regulamento interno, porém não ilegais, caracterizados pelo absenteísmo, não realização de trabalhos escolares e falta de respeito entre estudantes e deles em relação à equipe escolar. As indisciplinas registradas pareceram, por sua vez, corresponder ao conceito de incivilidade (CHARLOT, 2002; ABRAMOVAY; CUNHA; CALAF, 2009).

Nascente, Luiz e Fonseca (2015) explicam que hoje não é a violência que prevalece na escola, mas sim a indisciplina, que se constitui majoritariamente em atos de incivilidade e minoritariamente em atos de agressividade, posicionamento sustentado por Foucault (1984) e Ratto (2007). Os autores consideram indisciplinas como rupturas em relação às regras disciplinares estabelecidas pelas escolas, justamente o que foi encontrado nos LOE pesquisados, nos quais diferentes membros da equipe escolar expressaram discrepâncias qualitativas e quantitativas em relação aos registros de atos semelhantes entre meninas e meninos.

Assim, foi identificada uma imbricação entre atos de indisciplina e violência atribuídos a estudantes e seus respectivos gêneros, isto é, pareceu haver diferença no disciplinamento de meninas e meninos. Nessa perspectiva, entende-se que masculinidade e feminilidade fazem parte de um processo historicamente discriminatório que tem forte influência nas formas de agir e de se expressar de crianças e jovens dentro e fora da escola.

(C) Rev. Educ. Perspec.

Viçosa, $M G$

v.8

n. 2

p.159-176

\begin{tabular}{l|l} 
maio/ago. 2017 & eISSN 2178-8359
\end{tabular} 
A maneira como homens e mulheres se comportam em sociedade faz parte de um aprendizado sociocultural (LOURO, 1999). Antes mesmo do nascimento já existe uma expectativa social na formação do sujeito, atribuindo maneiras mais delicadas para meninas e mais grosseiras para os meninos. Nessa perspectiva, pode-se afirmar que:

há uma expectativa social em relação à maneira como homens e mulheres devem andar, falar, sentar, mostrar seu corpo, brincar, dançar, namorar, cuidar do outro, amar, etc (BRASIL, 2009, p. 40).

Quando chegam à escola, meninos e meninas agem de acordo com papéis socialmente atribuídos a eles, mormente, pela família, tendência reforçada pelas equipes escolares. Portanto a ação da escola no que se refere aos gêneros não é neutra, mas enraizada nos valores culturais das suas equipes. Além do ambiente escolar propriamente dito, há que se considerarem outros aspectos importantes na educação escolar, por exemplo, segundo Meyer, Klein e Andrade (2007) os estereótipos estão presentes nos materiais didáticos e avaliativos que contribuem para a perpetuação de um padrão de masculinidade e feminilidade construído e imposto pela sociedade. Para os autores, além de proporcionar vivências que reforçam esses estereótipos, a escola os ensina formalmente, pela associação gênero/sexualidade, sob uma visão biológica, no ensino de ciências, por exemplo.

Historicamente, a diferença social e cultural entre homens e mulheres foi vista como biológica, natural e invariável, mantendo-se incontestada por toda uma produção intelectual que enfatizava a inferioridade feminina. Esperava-se que os homens e as mulheres assumissem papéis distintos na sociedade: os homens eram destinados à esfera pública enquanto as mulheres à esfera privada. Ainda no século XX defendia-se que as diferenças comportamentais entre os sexos resultavam das suas diferenças biológicas. Segundo essa perspectiva, homens seriam mais fortes, menos resilientes, teriam melhores capacidades espaciais, numéricas e mecânicas, e veriam, tendencialmente, o mundo em termos de objetos, ideias e teorias. Mulheres, por sua vez, atingiriam maturidade física e psicológica mais cedo que os homens e seriam mais sociáveis e maternais. Elas também se desenvolveriam mais precocemente, apresentariam melhor competência verbal e veriam o mundo de um ponto de vista pessoal, harmonioso e ético.

Portanto, é essencial atentar-se ao fato de que "a ideia de 'inferioridade' feminina foi e é socialmente construída pelos próprios homens e pelas mulheres ao longo da história" (BRASIL, 2009, p. 39).

Os estudos que se voltaram à mudança desse quadro se constituíam em descrições das condições de vida e de trabalho das mulheres em diversas situações e espaços e possibilitaram evidenciar a discriminação social por elas sofrida. Segundo Louro (1999, p. 17-18), "estudos das áreas de Antropologia, Sociologia, Educação, Literatura etc. apontam as

\begin{tabular}{l|c|c|c|c|c|c} 
() Rev. Educ. Perspec. & Viçosa, $M G$ & v.8 & n.2 & p.159-176 & maio/ago. 2017 & eISSN 2178-8359 \\
\hline
\end{tabular}


desigualdades sociais, políticas, econômicas, jurídicas, denunciando a opressão e submetimento feminino".

Segundo a autora Louro (1999), o pensamento sobre a diferença social precisou ser compreendido não a partir das características sexuais, mas na forma como essas características eram representadas ou valoradas na sociedade, em determinados períodos históricos. O debate sobre homem e mulher passou a ser para além do sexo, surgindo uma nova linguagem na qual o conceito de gênero se tornou fundamental, segundo os Parâmetros Curriculares Nacionais (BRASIL, 1998, p. 321-322):

\begin{abstract}
O conceito de gênero diz respeito ao conjunto das representações sociais e culturais construídas a partir da diferença biológica dos sexos. Enquanto o sexo diz respeito ao atributo anatômico, no conceito de gênero toma-se o desenvolvimento das noções de "masculino" e "feminino" como construção social. O uso desse conceito permite abandonar a explicação da natureza como a responsável pela grande diferença existente entre os comportamentos e lugares ocupados por homens e mulheres na sociedade.
\end{abstract}

Para Lima e Salles (2014, p. 23) as discussões que vem sendo realizadas sobre gênero e sexualidade não parecem suficientes para superar a desigualdade, pois as autoras consideram que "ainda hoje predomina socialmente um pensamento dicotômico, polarizado, em que homem/mulher são concebidos como polos opostos e numa relação de dominação/submissão que parece se perpetuar".

Apesar dessa situação, é possível considerar que se o gênero faz parte de uma construção histórico social na qual os acordos sociais podem ser modificados e a igualdade de acesso aos direitos sociais, políticos e civis para homens e mulheres pode ser conquistada (BRASIL, 2009). Para isso é preciso compreender que:

igualdade não significa homogeneidade, isto é, o não reconhecimento de diferenças entre as pessoas. Por exemplo, não se pode pensar que tratar do mesmo modo uma criança, um adulto, ou um idoso seja igualdade. Obter igualdade exige a disposição de reconhecer o direito de cada um em ter reconhecidas suas necessidades. $\mathrm{O}$ direito em ter diferenças reconhecidas é que constitui a equidade (SPOSATI, 2010, p. 01).

Nesse contexto, a escola pode contribuir para reforçar a situação de desigualdade entre os gêneros:

educadores e educadoras têm a possibilidade de reforçar preconceitos e estereótipos de gênero, caso tenham uma atuação pouco reflexiva sobre as classificações morais existentes entre atributos masculinos e femininos e se não estiverem atentos aos estereótipos e aos preconceitos de gênero presentes no ambiente escolar (BRASIL, 2009, p. 51).

Assim, pode se pensar que considerar meninas mais organizadas e quietas e meninos mais bagunceiros e rebeldes deve influenciar as condutas de educadores em diferentes situações

\begin{tabular}{l|l|l|l|l|l|l} 
() Rev. Educ. Perspec. & Viçosa, $M G$ & v.8 & n.2 & p.159-176 & maio/ago. 2017 & eISSN 2178-8359 \\
\hline
\end{tabular}


escolares. Os estereótipos que apresentam meninos como mais agressivos do que meninas parecem ter se reproduzido e perpetuado nas escolas, o que pode influenciar práticas disciplinares, ou seja, espera-se que as meninas se adequem mais facilmente à tradicional disciplina escolar do que os meninos. Elas seriam mais afeitas a permanecer em sala de aula, obedecer aos professores e cumprir as tarefas do que os meninos. Apesar dessa visão relativamente estanque, para Abramovay e Cunha (2009), violência e indisciplina parecem também fazer parte do cotidiano escolar das meninas.

No que diz respeito aos LOE, em seus diferentes formatos e denominações, parecem ser instrumentos de disciplinamento bastante tradicionais e comuns nas escolas públicas brasileiras, como comprovaram as pesquisas de Moro (2003); Hermínio (2014); Fonseca, Salles e Silva (2014) e Vóvio et al. (2016). Talvez essa seja a razão pela qual estejam tão naturalizados pelas equipes escolares, naturalização comprovada pela pesquisa na qual se baseia este artigo.

Foucault (2013) refere-se frequentemente às disciplinas como técnicas de fabricação de indivíduos dóceis e úteis. Esse é o objetivo genérico do poder disciplinar: para além dos objetivos específicos que caracterizam o papel de cada instituição, visa incrementar ao máximo a docilidade e a utilidade dos indivíduos. A docilidade refere-se a um valor mais diretamente político, no sentido da diminuição máxima das resistências que possam ocorrer durante o exercício de qualquer tipo de poder. Trata-se de imprimir nos corpos tendências gerais à obediência, à colaboração, à maleabilidade e à condução.

Ratto (2007), que estudou questões disciplinares baseando-se em narrativas contidas em LOE de uma escola paranaense de anos iniciais do ensino fundamental, explica que:

\footnotetext{
os livros de ocorrência compõem uma problemática delicada e, diante de políticas e discursos humanizantes, emancipadores ou democratizantes, que permeiam o campo educacional, são às vezes vistos como algo execrável ou constrangedor, uma espécie de "mal necessário", a que as autoridades escolares recorrem para assegurar a sobrevivência diária da instituição (RATTO, 2007, p. 21).
}

$\mathrm{Na}$ pesquisa realizada, esse mal necessário, os LOE, expressam, entre diversos outros aspectos da vida escolar, como meninos e meninas são tratados de maneiras diversas ao infringirem o disciplinamento imposto pela escola.

O gráfico a seguir apresenta o índice de ocorrências por gênero em 10 LOE, um por turma, selecionados aleatoriamente. Esses livros ficavam armazenados na sala da coordenação da escola e foram disponibilizados para pesquisa no local. É possível notar preponderaram as ocorrências sobre meninos, mas que em certas turmas os registros sobre meninas se sobressaíram, chegando a se nivelarem com os dos meninos.

\begin{tabular}{l|l|l|l|l|l|l} 
(ㅇ Rev. Educ. Perspec. & Viçosa, $M G$ & v.8 & n.2 & p.159-176 & maio/ago. 2017 & eISSN 2178-8359 \\
\hline
\end{tabular}


Gráfico 1. Ocorrências por gênero em 2013

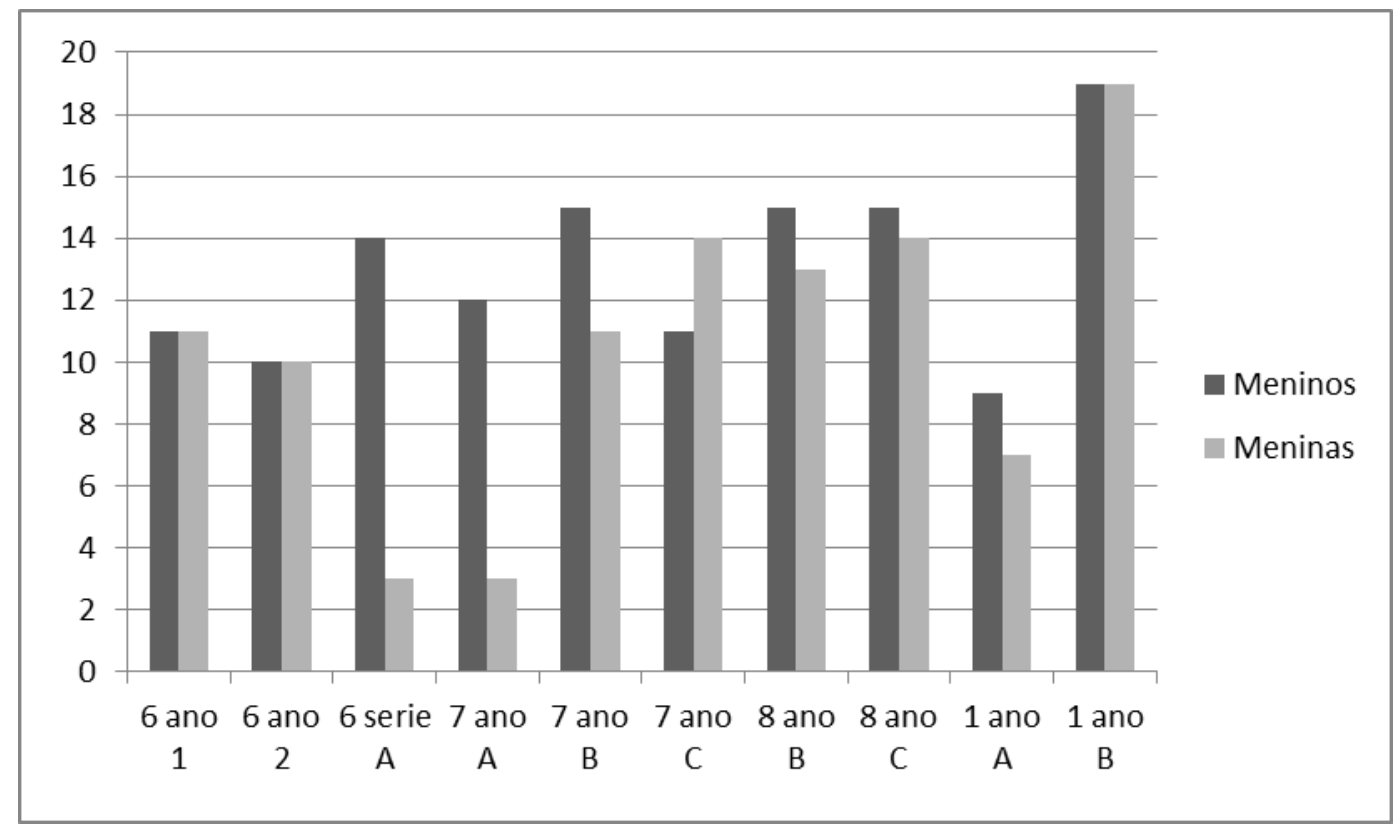

Fonte: As autoras

Primeiramente deve-se esclarecer que a existência de dois sextos anos (01 e 02) e uma sexta série (A) deveu-se à fase de transição entre o ensino fundamental de oito anos para o de nove anos que ocorreu naquele período nas escolas da rede estadual paulista. Outro esclarecimento importante é que nas turmas as quais se referiam os LOE eram numericamente proporcionais entre meninas e meninos. Interessante observar que, em duas turmas de $6^{\circ}$ anos, os índices foram os mesmos, porém, em outra turma do mesmo nível houve significativa discrepância. Esses dados levam a crer que quem registra imprime seus valores às ocorrências, isto é, provavelmente quem realizou os registros no $6^{\circ}$ ano no qual houve significativa diferença entre meninos e meninas tinha em mente que, como assevera Louro (1999), meninos envolvem-se mais em situações de indisciplina do que meninas. Também poderia ser o caso de que os mesmos atos cometidos por meninas e meninos fossem percebidos de formas diferentes por quem os registrou. Assim, aparentemente, concepções sobre gênero podem ser consideradas preditoras de como alguns educadores lidam com questões disciplinares. É possível que faça parte de uma aprendizagem sociocultural relativa aos gêneros esperar que meninos sejam mais indisciplinados do que meninas.

Segundo Hermínio (2014), ao relacionar violência e gênero em duas escolas estaduais paulistas, havia muitas contradições e conflitos no tratamento dado pelos professores às meninas e aos meninos. Em algumas situações eram assumidos posicionamentos mais tradicionais, em outras, maior respeito à diversidade era evidenciado. A autora atribui esse

\begin{tabular}{l|l|l|l|l|l|l} 
() Rev. Educ. Perspec. & Viçosa, $M G$ & v.8 & n.2 & p.159-176 & maio/ago. 2017 & eISSN 2178-8359 \\
\hline
\end{tabular}


quadro à falta de formação em estudos de gênero nos cursos de licenciatura. Entende-se que além desse fator importante, ocorre a prevalência de crenças socialmente construídas, concretizadas em certo senso comum, que reforçam estereótipos de como devem se comportar meninos e meninas na escola, refletidas nas atitudes tomadas por professores quando instados a lidar com atos de indisciplina.

No quadro 01 são apresentadas as categorias de análise, que aglutinaram a maior parte das ocorrências registradas nos LOE, objetivando o aprofundamento da discussão sobre as discrepâncias nos registros de ocorrências de atos de meninos e meninas.

Quadro 1. Ocorrências registradas por gênero em 2013

\begin{tabular}{|c|c|c|c|c|}
\hline Categorias & Tipos de ocorrências & Meninos & Meninas & TOTAL \\
\hline 1. Tarefas & $\begin{array}{l}\text { Não faz ou fez atividades/ tarefas; não termina/ } \\
\text { demora a fazer lição/ faz de qualquer jeito; não quer } \\
\text { fazer lição/ se recusou a participar da atividade; não } \\
\text { traz o material para escola/ não vem à escola; não } \\
\text { tirou o material da mochila/ não abre o caderno e } \\
\text { não tem matéria no caderno. }\end{array}$ & 338 & 168 & 506 \\
\hline $\begin{array}{l}\text { 2. Conversas } \\
\text { gritos e ruídos }\end{array}$ & $\begin{array}{l}\text { Conversa demais/ o tempo todo; brincadeiras/ } \\
\text { atrapalha a aula; fala alto/grita; conversa com } \\
\text { colega e assobia/ ruídos/ imitações. }\end{array}$ & 136 & 99 & 235 \\
\hline 3. Circulação & $\begin{array}{l}\text { Anda ou corre pela sala/ não fica no seu lugar/ } \\
\text { levanta toda hora; chegou atrasado à aula/ não } \\
\text { estava na sala de aula quando o professor chegou/ } \\
\text { não retornou para a sala de aula/ não entrou na aula; } \\
\text { sai da sala sem autorização/ sai na troca de aulas e } \\
\text { fugiu da escola/ saiu da escola sem autorização. }\end{array}$ & 220 & 77 & 297 \\
\hline $\begin{array}{l}\text { 4. Uso de } \\
\text { equipamentos }\end{array}$ & $\begin{array}{l}\text { Uso do celular durante a aula; com fone de ouvido; } \\
\text { celular retirado pelo professor/ direção; celular } \\
\text { ligado/ tocou durante a aula/ escutando música sem } \\
\text { fone e tirou fotos e fez vídeos com o celular dentro } \\
\text { da sala de aula. }\end{array}$ & 62 & 47 & 109 \\
\hline $\begin{array}{l}\text { 5. Desrespeito ao } \\
\text { professor }\end{array}$ & $\begin{array}{l}\text { Desrespeito ao professor; responder ao professor; } \\
\text { desobedecer ao professor; atrapalhar o professor e } \\
\text { gritar com o professor. }\end{array}$ & 162 & 18 & 180 \\
\hline
\end{tabular}

Fonte: As autoras

No que se refere à discussão entre a preponderância de atos de violência, agressividade e incivilidade (CHARLOT, 2002), fica evidenciado que a maior parte das ocorrências refere-se aos atos de incivilidade. Somente a categoria desrespeito ao professor poderia ser entendida como manifestação de agressividade e/ou violência, entretanto, só uma análise qualitativa desses dados poderia definir essa diferença. Também teria que ser entendida qual a noção de

\begin{tabular}{l|l|l|l|l|l|l} 
(C) Rev. Educ. Perspec. & Viçosa, $M G$ & v.8 & n.2 & p.159-176 & maio/ago. 2017 & eISSN 2178-8359 \\
\hline
\end{tabular}


respeito que permeou esses registros. É importante enfatizar que também havia registros de conflitos entre estudantes, mas as cinco categorias analisadas foram selecionadas em função de sua superioridade numérica nos registros.

Discrepâncias significativas nos registros em LOE também foram explicitadas na pesquisa desenvolvida em duas escolas por Vóvio et al. (2016). Em uma das escolas, o número de registros de indisciplina foi expressivamente superior ao de outra. Para os autores, a escola que mais registrou pode tê-lo feito em função "de um sistema de controle de comportamentos que interferem diretamente na relação professor-aluno, sistema esse constituído com base no que a escola concebe como adequado" (p. 20). Então, a indisciplina também poderia ser entendida como "uma reação ao controle exercido pelas escolas" (p. 20).

Atos de indisciplina de meninos foram, como demonstra o quadro, significativamente mais registrados do que os de meninas. As diferenças mais radicais se referem às categorias "circulação" e "desrespeito ao professor". Os meninos são os protagonistas nessas categorias, confirmando os estereótipos de gênero atribuídos à masculinidade, maior independência/ liberdade de ir e vir e também maior agressividade. Esse dado também confirma os estereótipos comumente atribuídos à feminilidade: placidez e menor potencial de agressividade. Pode-se inferir assim que, principalmente no que concerne à categoria desrespeito ao professor, as meninas continuam respondendo às expectativas da sociedade.

Por outro lado, também é possível que, ao se esperar que meninas pratiquem menos atos de indisciplina, mesmo eles sendo praticados, são menos frequentemente registrados. Isso pode estar ligado à educação moral dada às meninas, que pode ser entendida como um leque de prescrições, códigos morais e regras de comportamento, colocados de modo sistemático ou difuso, explícito ou implícito (FOUCAULT, 1998).

Portanto, os registros nos LOE parecem explicitar que seus autores estavam comprometidos com uma moral voltada à obediência, à resignação, à docilidade, à conformação, características comumente atribuídas ao gênero feminino. Já o desrespeito a esse tipo de moral, a resistência a ela, pareciam ser atribuídos aos meninos. Demarcadora dessa posição moralizante e domesticadora da escola é a significativa frequência de ocorrências relativas a namoros e relacionamentos no ambiente escolar, que recaíram primordialmente sobre as meninas, evidenciadas pelos excertos a seguir:

Não faz as atividades de inglês, conversa muito e fala muito palavrão, aliás, fala mais palavrão do que qualquer menino na sala. Não tem interesse em nada, só pensa em namorar ( $7^{\mathrm{a}}$ série -2013 , grifos nossos).

Não estava fazendo a lição de português. Conversa o tempo todo e quando está junto com a Ana Beatriz literalmente não faz nada. Estava se agarrando em sala com sua amiga atrapalhando a aula ( $7^{\mathrm{a}}$ série -2013 , grifos nossos). 
Foi chamada a atenção da aluna e do namorado [...], várias vezes e vários dias durante as trocas de aula, pois os dois ficam namorando nos cantos dos corredores e não obedece de imediato o pedido da agente que o solicita para que entrem na sala. Eles retrucam, ignoram a agente. Eles parecem não conseguir compreender que no andar de cima, onde existem as sala de aula, é um local para se estudar e não ficar se agarrando, pois namorar tem local e tempo específico $\left(1^{\circ}\right.$ ano -2013$)$.

Beijando e abraçando um menino na sala de aula. Ainda chamou a professora de mentirosa $\left(1^{\circ}\right.$ ano -2013 , grifos nossos $)$.

Não realiza as atividades, quando pedi que ela realizasse, ela disse que estava com preguiça e que não iria fazer. Além disso, tem comportamentos inadequados para o ambiente da sala de aula. Passou toda a aula conversando com Aluna A ( $7^{\mathrm{a}}$ série 2013).

Os registros acima nos permitem afirmar que o gênero feminino é valorado de maneira diversa do masculino. Em somente um deles um menino e uma menina são colocados em condição de igualdade pela infração de estarem namorando em locais considerados como inadequados. Nos demais, como explica Louro (1999), se expressa uma expectativa de que meninas devem ser essencialmente mais dóceis do que meninos, noção que se concretiza no primeiro excerto, que apresenta a ideia de que meninas não devem falar palavrões, o que seria aceitável para meninos. Também é colocado que a menina só pensa em namorar, em tom condenatório. Agarrar-se em sala também não é atitude adequada às meninas, concepção expressa no segundo excerto. Interessante ainda é observar que, no penúltimo excerto, uma menina parece estar praticando sozinha o ato de beijar e abraçar um menino, este sendo apenas alvo passivo da ação, é como se só a menina estivesse cometendo um ato de indisciplina.

Esses registros dos atos das meninas considerados como indisciplinas remetem a um papel social no qual manifestar interesse afetivo e/ou ter iniciativa e ser protagonista em encontros amorosos não faz parte das atitudes esperadas de meninas, principalmente, quando se trata do espaço escolar, no qual ainda prevalece uma cultura na qual se espera que meninas sejam passivas e dóceis. Aliás, a docilidade pode ser um dos cernes dessa discussão. Se a escola quer formar sujeitos dóceis e meninas são vistas como mais dóceis, essa pode ser a razão pela qual há menos registros de ocorrências envolvendo meninas, por outro lado, poderia se inferir que atos de meninas que contradigam imagens de docilidade e passividade tenderiam a ser mais severamente punidos do que os mesmos atos praticados por meninos.

Quanto ao índice de registros nos quais os meninos eram protagonistas - que corresponde à maioria dos casos - é possível verificar inicialmente pelos excertos a seguir que os atos registrados são completamente diferentes dos das meninas. Enquanto os registros sobre meninas eram primordialmente sobre namoros e encontros, os sobre meninos foram predominantemente relativos à movimentação e atos de agressividade. Vale destacar também que as medidas tomadas são baseadas em ameaças e punições.

\begin{tabular}{l|c|c|c|c|c|c|} 
(C) Rev. Educ. Perspec. & Viçosa, $M G$ & v.8 & n.2 & p.159-176 & maio/ago. 2017 & eISSN 2178-8359 \\
\hline
\end{tabular}


O aluno pediu a professora para descer e pedir dispensa, pois estava com dor de barriga. O vice-diretor não permitiu a saída dele da escola, então subiu pegou o material e foi embora da escola, sem autorização e sem aviso ( $6^{\text {a }}$ série - ensino fundamental).

Não terminou a atividade proposta na sala de aula, além disso, ficou brincando de jogar bolinhas de papel nos outros colegas de classe. O professor o tirou da sala por motivo de tumulto. $\mathrm{O}$ aluno foi suspenso por um dia, devendo retornar no dia 22/10 acompanhado de um responsável ( $6^{\mathrm{a}}$ série - ensino fundamental).

Mandou o professor tomar literalmente no 'cú' e me ameaçou verbalmente sem condições de retornar a minha aula. Se este aluno permanecer na escola eu me retiro dessa sala de aula para sempre (foi suspenso por 03 dias) ( $8^{\text {a }}$ série - ensino fundamental).

Evadiu-se da escola sem autorização da Direção. Está suspenso por 03 dias. Somente retornará com a presença do responsável ( $1^{\circ}$ ano- ensino médio).

Outro aspecto a ser observado nas ocorrências acima é que elas correspondem a certo estereótipo de masculinidade. Como meninos são considerados mais corajosos, agressivos e independentes, o tom dos registros difere daquele expressado nas ocorrências referentes a meninas, nas quais não há menção a punições. Já no último excerto referente a meninos o termo evadiu-se possui certa conotação de independência, o sujeito como autor do ato de evasão, além de certo matiz policialesco, o que não se aplicaria ao estereótipo de feminilidade encontrado nos registros. Diferentemente dos registros sobre meninas, nos relativos a meninos, as punições, por sinal bastante rígidas, foram registradas e provavelmente aplicadas.

Como evidenciam os excertos, as principais medidas disciplinares adotadas pela escola em relação aos meninos foram advertências e suspensões, que podiam variar de um a três dias, além da transferência compulsória, que na verdade é uma forma de expulsão, pois obriga o estudante a ir para outra escola. Nota-se que não há consenso sobre como as medidas disciplinares devem ser aplicadas, uma vez que atos de indisciplina similares foram encaminhados de diferentes formas. A gravidade pareceu ser decidida de maneira bastante subjetiva, de acordo com o membro da equipe escolar que fazia o registro.

Há ainda a possibilidade de que os atos de indisciplina praticados por meninos possam ter sido entendidos como naturais, como parte da construção do gênero masculino, ajudando-os a instituir e consolidar sua masculinidade. Já os atos das meninas poderiam causar maior espanto, principalmente os de agressividade, pois eles seriam contrários ao estereótipo de feminilidade. Portanto, punir meninos com mais rigor do que meninas faz todo sentido, pois punir severamente seria a forma adequada de educar meninos. Já as meninas, por serem consideradas mais passivas, poderiam ser punidas de formas mais sutis, mas não menos repressivas. 
A respeito dos motivos das agressões e incivilidades praticadas por meninas, tais como fofocas, ciúmes, disputas por namorados, intrigas e inveja, eles se constituíram em disputas relacionadas à autoridade masculina (ABRAMOVAY; CUNHA; CALAF, 2009). Os conflitos entre meninas teriam sua origem em disputas por meninos, o gênero feminino, na questão disciplinar, orbitaria em torno do masculino. Já os atos de meninos seriam totalmente independentes de suas relações com meninas.

Os registros nos LOE indicaram a vigência de relações de gênero estereotipadas, marcadas por concepções tradicionais de como meninas e meninos devem se portar. Essas relações permeiam toda a vida escolar e parecem se constituir em mais um aspecto a ser levado em consideração na problemática relativa à indisciplina e violência na escola. Ao tentar manter meninos e meninas em determinados espectros de atitudes na busca de discipliná-los para obedecer e seguir regras, a escola se torna terreno fértil para antagonismos cada vez mais radicais entre estudantes e entre eles e a equipe escolar.

Esses antagonismos podem levar meninas e meninos a considerar a escola um território onde reina a injustiça. Schilling e Angelucci (2016) explicam como nas escolas se configuram jogos complexos de reprodução e transformação, comprovando que para a democratização das escolas seria necessário trabalhar com os dissensos de forma a ir gradativamente construindo relações escolares mais igualitárias, abrindo caminho para uma escola mais justa. Botler (2016) corrobora essa perspectiva demarcando a dificuldade que as equipes escolares e estudantes têm em distinguir práticas justas de injustas. Podemos inferir então, que as meninas e os meninos que tiveram seus atos registrados nos LOE envolveram-se em conflitos, que desembocaram em situações tanto de indisciplina como de violência, como uma reação a diversas injustiças que vinham sofrendo na escola, mas não conseguiam compreendera, entre elas as relativas ao tratamento diferenciado dado aos gêneros.

\section{ALGUMAS CONSIDERAÇÕES}

Os registros nos LOE se constituíram em fontes muito ricas não só para a compreensão da problemática da violência e indisciplina na escola, mas de diversos aspectos do cotidiano escolar, com destaque para as questões de gênero.

No que se refere à violência na escola, o que tem sido verificado é que, na maior parte dos registros, os atos são de incivilidade e uma menor parte de agressividade. Os casos de agressividade verbal e física entre estudantes e entre eles e membros da equipe escolar poderiam eventualmente ser considerados atos de violência. Então o que se pode concluir é que a visão da escola como uma instituição violenta pode ser entendida como uma mistificação, muito alimentada pelas diversas mídias.

\begin{tabular}{l|c|c|c|c|c|c|} 
(C) Rev. Educ. Perspec. & Viçosa, $M G$ & v.8 & n.2 & p.159-176 & maio/ago. 2017 & eISSN 2178-8359 \\
\hline
\end{tabular}


Além disso, os registros evidenciaram diversos preconceitos, com destaque para os relativos aos gêneros. Isto é, a perspectiva tradicional e estereotipada dos gêneros masculino e feminino perpassou os registros, dificultando que as pesquisadoras e, provavelmente, a própria equipe escolar, tivessem uma visão mais clara dos atos realmente como ocorridos, o que deve dificultar a elaboração de encaminhamentos eficazes do ponto de vista formativo.

Punições escancaradas e em alguns casos exageradas para meninos e mais sutis, mas provavelmente não menos severas para meninas, criam relações antagônicas entre estudantes, entre eles e membros da equipe escolar, ecoando nas famílias e na comunidade, o que tende a dificultar a adesão de estudantes e suas famílias às propostas pedagógicas da escola, inibindo o estabelecimento e fortalecimento de relações profícuas de ensino e aprendizagem, na perspectiva da qualidade social da educação e dos direitos humanos fundamentais.

\section{REFERÊNCIAS}

ABRAMOVAY, Miriam; RUA, Maria das Graças. Violências nas escolas. Brasília: UNESCO, Instituto Ayrton Senna, UNAIDS, Banco Mundial, USAID, Fundação Ford, CONSED, UNDIME, 2002.

ABRAMOVAY, Miriam; CUNHA, Anna Lúcia; CALAF, Priscila Pinto. Revelando tramas, descobrindo segredos: violência e convivência nas escolas. Brasília: Rede de Informação Tecnológica Latino-americana - RITLA, Secretaria de Estado de Educação do Distrito Federal - SEEDF, 2009.

BOGDAN, Robert; BIKLEN, Sari Knopp. K. Investigação qualitativa em educação: uma introdução à teoria e aos métodos. Porto: Porto Editores, 2010.

BOTLER, Alice Miriam Happ. Injustiça, conflito e violência: um estudo de caso em escola pública de Recife. Cadernos de Pesquisa, v. 46, n. 161, p. 716-732, jul./set., 2016.

BOURDIEU, Pierre. O poder simbólico. Lisboa: Difel, 1989.

BRASIL. Secretaria de Educação Fundamental. Parâmetros curriculares nacionais. Brasília: MEC/SEF, 1998.

BRASIL. Gênero e diversidade na escola: formação de professoras/es em gênero, orientação sexual e relações étnico-raciais. Brasília: SPM, 2009.

CHARLOT, Bernard. A violência na escola: como os sociólogos franceses abordam essa questão. Sociologias, Porto Alegre, n. 8, p. 432-443, 2002.

(C) Rev. Educ. Perspec.

Viçosa, $M G$

v.8

n.2

p.159-176

maio/ago. 2017 eISSN 2178-8359 
DEBARBIEUX, Eric. Violência na escola: um desafio mundial? Lisboa: Instituto Piaget, 2007.

FONSECA, Débora Cristina; SALLES, Leila Maria Ferreira; SILVA, Joyce Mary. Contradições do processo de disciplinamento escolar: os "Livros de Ocorrências" em análise. Revista Quadrimestral da Associação Brasileira de Psicologia Escolar e Educacional, São Paulo. v. 18, n. 1, p. 35-44, 2014.

FOUCAULT, Michel. Vigiar e punir: nascimento da prisão. Petrópolis, RJ: Vozes, 1984.

FOUCAULT, Michel. História da sexualidade 2: o uso dos prazeres. Rio de Janeiro: Graal, 1998.

GIL, Antônio Carlos. Como elaborar projetos de pesquisa. São Paulo: Atlas, 2002.

HERMINIO, Ana Beatriz. Violência escolar e a expectativa de comportamento feminino: percepções de professores/as e diretores/as presentes nos registros de cadernos de Ocorrência. 2014, 118 f. Dissertação (Mestrado em Educação) - UNESP, Rio Claro.

LIMA, Maria Teresa; SALLES, Leila Maria Ferreira. Alterações de um olhar cristalizado dos educadores para seus alunos e alunas. Revista Educação: teoria e prática, São Paulo: Instituto de Biociências da UNESP - Rio Claro, v. 24, n. 45. p. 17-54, jan/abr. 2014. LOURO, Guacira Lopes. Gênero, sexualidade e educação: uma perspectiva pósestruturada. Petrópolis: Vozes, 1999.

LOURO, Guacira Lopes. Gênero, sexualidade e educação: uma perspectiva pósestruturalista. Petrópolis: Vozes, 2007.

MEYER, Dagmar; KLEIN, Carin; ANDRADE, Sandra dos Santos. Sexualidade, prazeres e vulnerabilidade: implicações educativas. Educação em Revista. Belo Horizonte: Faculdade de Educação da Universidade Federal de Minas Gerais, n. 46. p. 219-239, dez. 2007.

MORO, Neiva de Oliveira. O livro preto nas escolas da região dos Campos Gerais. In: JORNADA DO HISTEDBR, 2003, Campinas. Anais..., Campinas: Unicamp, p. 01-13, 2003.

NASCENTE, Renata Maria Moschen; LUIZ, Maria Cecília; FONSECA, Débora Cristina Conflitos e livros de ocorrência no cotidiano da escola pública: alguns caminhos de investigação. In: $37^{a}$ Reunião da ANPEd, 2015, Florianópolis. Anais..., Florianópolis: ANPEd, p. 01-19, out. 2015.

RATTO, Ana Lúcia Silva. Livros de ocorrência: (in) disciplina, normalização e subjetivação. São Paulo: Cortez, 2007.

SPOSATI, Aldaíza. Equidade. In: OLIVEIRA, Dalila Andrade; DUARTE, Adriana Cancella; VIEIRA, Lívia Fraga. Dicionário: trabalho, profissão e condição docente. Belo Horizonte: UFMG/Faculdade de Educação, 2010.

\begin{tabular}{l|c|c|c|c|c|c} 
(C) Rev. Educ. Perspec. & Viçosa, $M G$ & v.8 & n.2 & p.159-176 & maio/ago. 2017 & eISSN 2178-8359 \\
\hline
\end{tabular}


SCHILLING, Flávia. ANGELUCCI, Carla Bianca. Conflitos, violências, injustiças na escola? Caminhos possíveis de uma escola justa. Cadernos de Pesquisa, v. 46, n. 161, p. 694-715, jul./set., 2016.

VÓVIO, Cláudia Lemos; RIBEIRO, Vanda Mendes; NOVAES, Luiz Carlos; BRAVO, Maria Helena. Livros de ocorrência: violência e indisciplina em escolas de território vulnerável. Arquivos Analíticos de Políticas Educativas, v. 24, n. 126, p. 1-29, 2016. 


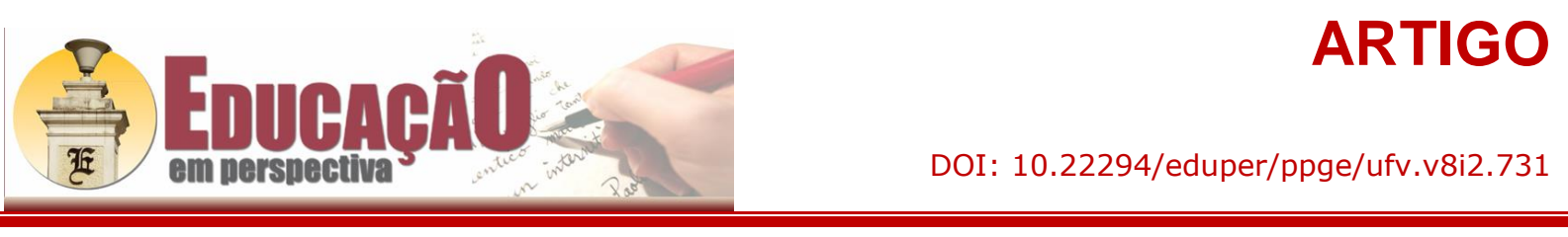

\section{Agradecimentos}

Ao CNPq pelo financiamento desta pesquisa.

\section{Sobre as autoras}

${ }^{\mathrm{i}}$ Renata Maria Moschen Nascente - Professora adjunta do Departamento de Educação da Universidade Federal de São Carlos. Mestre e Doutora em Educação pela Faculdade de Ciências e Letras da UNESP (Araraquara). E-mail: rmmnascente@gmail.com

${ }^{\text {ii } M a r i a ~ C e c i ́ l i a ~ K e r c h e s ~ d e ~ M e n e z e s ~-~ M e s t r a ~ e m ~ E d u c a c ̧ a ̃ o ~ p e l a ~ U n i v e r s i d a d e ~ E s t a d u a l ~ P a u l i s t a . ~ E-~}$ mail: ckerches@gmail.com

iii Paola Karuliny Guarnieri - Mestranda em Educação pela Universidade Federal de São Carlos. Email: paolakguarnieri@gmail.com 